\title{
Aplicação do conceito de modularidade - foco em usuários novatos
}

\author{
Application of the concept of modularity - focus on novice users
}

Lisandra de Andrade Dias

Design, Ergonomia, Usabilidade

\begin{abstract}
Este trabalho buscou, nos conhecimentos da cognição situada e do conceito de modularidade, base teórica para atingir seu objetivo geral: aplicar o conceito de modularidade na proposta de construção de um modelo de análise de interfaces digitais de um telefone celular com ênfase em usuário novatos. Partindo do embasamento teórico e das experiências anteriores com a aplicação desse conceito em uma hipermídia adaptativa (ambiente TelEduc) e em uma hipermídia de comunicação e relacionamentos (Gmail), foi gerada a hipótese de aplicação do mesmo em um aparato tecnológico de comunicação - no caso, o telefone celular Nokia 2660. Para a construção do modelo de análise foi realizada uma avaliação heurística da interface digital. Os resultados obtidos fazem crer que a hipótese foi alcançada.
\end{abstract}

Design, Ergonomics, Usability

This paper is founded on studies of situated cognition and on the concept of modularity, theoretical groundwork to reach its general goal: to apply the concept of modularity in the proposal of constructing a framework for analysis of digital interfaces of a cellular telephones, with emphasis on novice users. Departing from this theoretical groundwork and on previous experience with the application of the referred concept in an adaptive hypermedia (Tel Educ's distance learning environment) and in a communication and relationships hypermedia (Gmail), it was proposed the hypothesis of application of the same concept in a technological apparatus of communication: the cellular telephone Nokia 2660. For the construction of the analytical framework, a heuristic evaluation of the digital interface was carried out. The results achieved lead to believe that the hypothesis was confirmed.

\section{Introdução}

Este trabalho tem sua fundamentação teórica no Conceito de Modularidade (Dias, 2008) para concepção de ambientes condutivos e intuitivos com ênfase em usuários novatos para atingir seu objetivo geral: aplicar o Conceito de Modularidade na proposta de construção de um modelo de análise de interfaces digitais de um telefone celular.

A escolha pelo telefone celular se deu, devido (i) ao número expressivo de usuários deste aparato tecnológico. A quantidade de celulares superou o número de habitantes no Brasil, em novembro de 2010, com 194,4 milhões de celulares (Tavares, 2010); (ii) ao desenvolvimento de interfaces digitais totalmente diferenciadas por parte de cada uma das empresas fabricantes desse aparato tecnológico; (iii) à inexistência de garantia, por parte de algumas empresas deste segmento, de homogeneidade nas interfaces digitais entre seus diversos modelos, implicando na necessidade do usuário de aprender a nova interface digital a cada aquisição de um novo equipamento - seja este de um diferente fabricante ou de um diferente modelo de uma mesma empresa.

\section{Conceito de modularidade}

O Conceito de Modularidade é uma convergência dos conhecimentos da Cognição Situada (Clancey, 2005; Gibson, 1987; Grison, 2004; Hutchins, 2000; Lave, 1998; Suchman, 1987; Theureau, 2004; Vanzin, 2005) e da Hipermídia Adaptativa e Adaptável (Brusilovsky et al., 2004). 
A partir da fundamentação teórica em cognição situada, compreende-se que a ação situada está embasada na forte influência do contexto para a compreensão e para a tomada de decisão. Assim, todos os elementos excessivos e pouco pertinentes para uma ação podem induzir ao erro e atrapalhar o aprendizado da interface do ambiente.

A aprendizagem situada apoia-se no princípio de que o conhecimento precisa ser apresentado e aprendido no contexto real do indivíduo durante a atividade. Requer a introjeção dos termos e significados, com seus respectivos valores, associados às ações de quem as está realizando. Ainda, deve proporcionar uma formação individualizada e flexível que atenda ao ritmo cognitivo de cada indivíduo.

Os estudos da consciência situada ressaltam a importância e a influência do contexto e da situação na interação e na tomada de decisão do usuário com a interface. Suchman (1987), Lave (1988) e Endsley (1995) afirmam a necessidade de disponibilizar apenas os elementos pertinentes à tarefa e, com isso, simplificar os elementos da interface. Essa simplificação, tangente à definição da quantidade e da precisão da informação a serem adquiridas pelo usuário, visa proporcionar uma melhoria na atenção e na redução da carga de trabalho durante a tarefa. Esses fatores são relevantes, principalmente, para os usuários novatos.

A partir dos estudos da ação, da aprendizagem e da consciência situada, foi proposto por Dias (2008) o Conceito de Modularidade, que tem como objetivo garantir aos usuários novatos um melhor desempenho na interação com interfaces digitais e com ambientes interativos. Conforme constatado na literatura pesquisada, deve-se proporcionar a simplificação da interface digital com o intuito de facilitar sua aprendizagem, bem como a interação e a tomada de decisão por parte dos usuários, principalmente os novatos.

A interface digital é o próprio contexto, logo, deve garantir ao usuário o conteúdo requerido sob demanda, guiado por um design centrado no usuário, respeitando o ritmo de desenvolvimento cognitivo deste, apoiado em uma abordagem pedagógica.

A aplicação do Conceito de Modularidade em interfaces digitais e em ambientes interativos pode ser oferecida nas áreas de conteúdo, de ferramentas ou em ambas, simultaneamente. No caso da modularidade de conteúdo, a disponibilização de materiais informacionais e de conteúdos deve ocorrer a partir da evolução do aprendizado dos usuários.

Quanto à sua aplicação na área de ferramentas, a modularidade visa garantir aos usuários uma adaptabilidade por grau de complexidade das ferramentas, ou seja, o usuário define o perfil da Interface Adaptativa e Adaptável (IAA), como novato, intermediário ou experiente para interação, perfis estes armazenados em uma Base de Modelos de Usuários (BMU). Para cada perfil, o sistema possui uma interface pré-estabelecida, com um determinado agrupamento de ferramentas relativas às tarefas a serem realizadas, determinado em função do grau de complexidade destas.

Figura 1: Proposta de Dias (2008): adaptação do modelo genérico de Brusilovsky (2004).

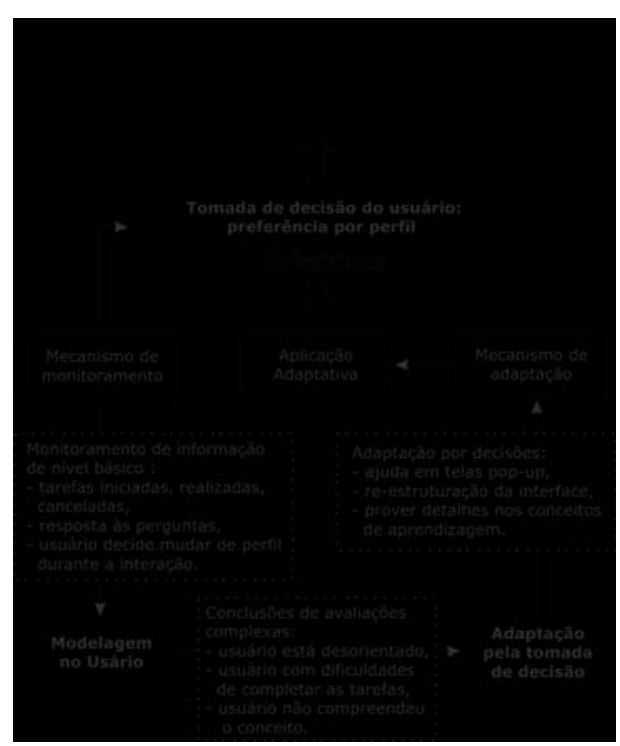


A Interface Adaptativa (IA) executa dois processos: (i) a apresentação de conteúdos e links adaptados ao modelo do usuário e (ii) a coleta de informações relevantes para mantê-lo atualizado. Geralmente a interface oferece um grau de interatividade, possibilitando ao usuário a adaptabilidade às suas preferências e permitindo a configuração de atributos como o tipo e tamanho do texto, cores, volume de áudio, tamanho das janelas, etc. O Conceito de Modularidade propõe disponibilizar ao usuário a escolha de um perfil com ferramentas respectivas às tarefas a serem realizadas - configurando-se, assim, uma interface adaptativa e adaptável (IAA).

$\mathrm{Na}$ estrutura de um ambiente modular, a modelagem da interface de ambiente por perfil de usuário pode ser realizada com os recursos de hipermídia adaptativa para a liberação de ferramentas de maneira progressiva, por objetivos como adequação ao repertório e experiência do usuário novato. Durante a interação, o sistema reconhece a evolução do usuário na realização das tarefas e libera uma nova interface com ferramentas anteriormente ocultadas, por exemplo: um usuário novato, depois de algumas sessões de interação, consegue realizar rapidamente e/ou com sucesso todas as tarefas respectivas ao perfil de novato, então o sistema libera, numa próxima interação, a interface de perfil de usuário intermediário. E assim sucessivamente, até que o usuário consiga atingir o nível de interface para experientes, na qual estarão disponíveis todas as ferramentas do sistema.

Essa liberação de ferramentas é provida pelo sistema de acordo com critérios como tempo de interação ou grau de complexidade da tarefa, determinados pelos projetistas da interface digital. Entretanto, a tomada de decisão é do usuário, ou seja, é ele quem determina o perfil de contexto com o qual estará interagindo, garantindo a adaptabilidade das ferramentas do ambiente. Assim, tira-se do sistema e atribui-se ao usuário a tomada de decisão, configurando-se uma abordagem antropocentrada.

É fundamental que se permita ao usuário a escolha de perfil. Desta forma, caso o sistema libere para um usuário novato a IA de um intermediário e o mesmo não se sinta seguro ou confortável com a nova interface, ele deve ter a opção de retornar à interface anterior apenas com um clique no comando. A adaptabilidade de mudança de perfil de usuário durante a interação deve atender à preferência do usuário.

Quanto aos critérios para a liberação das ferramentas em um ambiente modular, estes devem ser determinados de acordo com o tipo do ambiente e com os objetivos dos seus projetistas e gestores. Entretanto, acredita-se que é de suma importância que obedeçam a uma abordagem pedagógica.

O Conceito de Modularidade prevê que na primeira interação do usuário com a interface digital, este visualizará uma tela de apresentação que explicará que aquele ambiente opera com a proposição de módulos de ferramentas. Nessa tela de apresentação, deverá haver um breve questionário (um quiz) sobre a experiência e o repertório do usuário com o uso de software em geral e, especificamente, sobre o aparato tecnológico em questão, de forma que o sistema identificará o perfil do usuário pelas respostas.

Para usuários intermediários e experientes, propõe-se que a interface do ambiente mantenhase sempre na versão completa do ambiente, ou seja, com todas as ferramentas disponíveis para o seu aprendizado e utilização. Para os usuários novatos, o sistema deve apresentar uma mensagem na tela de apresentação, explicando que o sistema liberará um grupo de ferramentas a cada acesso à interface ou de acordo com a complexidade de suas tarefas, ou seja, segundo a variável determinada pelos projetistas. Na tela de apresentação subsequente, deve constar uma ressalva alertando o usuário que este pode mudar de perfil durante a interação, ou seja: mesmo tratando-se de um usuário novato, o sistema pode permitir a visualização da interface para os perfis intermediário ou experiente, permitindo o acesso à versão completa do ambiente. Tendo o usuário novato visualizado a versão completa do ambiente, ele poderá retornar ao seu perfil inicial, caso deseje.

Em uma proposta mais ampla, o usuário pode ser questionado diretamente sobre a relevância de cada unidade que será recuperada, de forma que o sistema coloque à sua disposição apenas as ferramentas relevantes, podendo o usuário decidir manter-se ou não com esse perfil.

Partindo deste embasamento teórico e das aplicações anteriores do Conceito de Modularidade em uma hipermídia adaptativa - ambiente TelEduc (Dias, 2008) e em uma hipermídia de comunicação e relacionamentos - Gmail (Dias, 2007), foi gerada a hipótese de aplicação do mesmo em um aparato tecnológico de comunicação - no caso, o telefone celular Nokia 2660. 


\section{Avaliação heurística}

Foi realizado um estudo sobre a complexidade das funcionalidades e de suas respectivas interfaces digitais para a determinação de uma tarefa com este equipamento. Para a coleta e análise dos dados e diagnóstico, foi realizada uma avaliação heurística que baseou-se nos "Princípios para o projeto da interação móvel" recomendados por Cybis et al (2007).

A partir da coleta e da análise de dados, constatou-se que são necessárias seis (06) ações para a realização da tarefa de realizar uma chamada telefônica selecionando o número pela lista de contatos deste telefone celular.

O sistema existente no equipamento analisado apresenta flexibilidade de adaptação de acordo com a experiência do usuário, desde que este tenha o domínio da realização da tarefa de criação de atalhos ou de configuração de equipamentos, característica de usuários experientes, não comum aos usuários novatos.

A tela Menu apresenta como padrão de acionamento imediato a opção da seção Galeria, que permite a visualização de imagens e, o download de videoclipes e arquivos de música, como se a função principal de um telefone celular fosse a visualização de imagens ou mesmo o uso do equipamento como um tocador de músicas.

Para o acesso à lista de contatos, o usuário novato necessita optar pela seção Contatos representada pelo ícone do livro com o telefone, sendo que na tela seguinte o mesmo ícone recebe a denominação Nomes. Os ícones garantem uma redução na carga cognitiva do usuário, pois diminuem a necessidade de memorização, desde que haja uma relação natural entre sua representação e o seu significado. Não é recomendado o uso em duplicidade de um mesmo ícone para diferentes comandos e/ou seções para qualquer perfil de usuário, pois isso pode confundi-lo no processo de interação e provocar um erro na realização da tarefa.

Ainda, na realização desta tarefa, percebeu-se que algumas telas apresentam barra de rolagem, fator desaconselhado para usuários novatos - que podem não perceber as informações não disponíveis na tela.

Compreende-se que a interface digital e o sistema do equipamento analisado apresentam certa complexidade para a realização da tarefa de discagem, principalmente se considerarmos o perfil de usuários novatos. Lembrando que Jones (2006) apud Cybis et al (2007) afirma que a interação com as telas pequenas tem custo elevado no que diz respeito a tempo e esforço cognitivo, devido principalmente ao fato de o usuário se perder durante a navegação, tornando a execução das tarefas entediante e, muitas vezes, frustrante.

Esse esforço cognitivo pode ser de diferentes ordens: a dificuldade de interação com a interface digital devido à complexidade da tarefa, um número extenso de ações para a realização da tarefa, ícones sem significado explícito ou redundância dos ícones. Ainda, o uso de telefonia móvel pode sofrer influência do ambiente onde o aparelho está sendo utilizado, por exemplo: o usuário pode ter déficit de atenção por estar em um local com muitos ruídos, o usuário e/ou o aparelho podem estar em movimento ou, ainda, podem estar sendo realizadas múltiplas atividades simultaneamente.

Sobre os princípios para o projeto da interação móvel, de um modo geral, pode-se dizer que:

- a interface não apresenta adequação ao contexto do usuário novato;

- as telas apresentam certa consistência externa, com o uso de ícones e metáforas semelhantes em outros modelos e em outros celulares;

- as telas apresentam parcial consistência interna quanto à estrutura de navegação e padrões de telas; entretanto, percebe-se a duplicidade de um ícone e o uso inconstante de barra de rolagem;

- a necessidade de um número considerável de ações para a realização da tarefa não proporciona uma minimização de custo, uma vez que quanto maior o tempo de uso do celular com a iluminação de tela, maior será a frequência de recarga do mesmo;

- o número excessivo de ações para a realização da tarefa acarretará uma carga cognitiva de interação, que também será agravada pela inconstância de significado do ícone representado pelo fone sobre o livro; 
- a interface não garante facilidade de navegação para os usuários novatos pois as opções de cada seção apresentam-se na forma de listas longas, o que poderia ser remediado com um melhor agrupamento;

- o apoio à seleção de opções está presente apenas no menu principal, com o intuito de informar brevemente sobre cada seção;

- a presença da barra de rolagem de tela é inconstante. O sistema de navegação não é padrão, ou seja, nas telas de Opções verifica-se a presença de barras de rolagem, enquanto na Lista de Contatos a navegação ocorre com o movimento da faixa azul de seleção (figura 2);

- o sistema garante parcialmente apoio às interrupções. A tela em visualização será mantida caso a ação seja interrompida, entretanto caso haja uma interrupção de ordem técnica, como finalização de bateria, não são recuperadas as ações, mas apenas os dados armazenados anteriormente;

- devido ao dimensionamento das telas, acredita-se que a interface não é um modo "miniaturizado" de outro aplicativo;

- garante apoio à personalização da interface apenas para usuários intermediários e experientes (figura 3 ).

Figura 2: Exemplo das duas opções de navegação

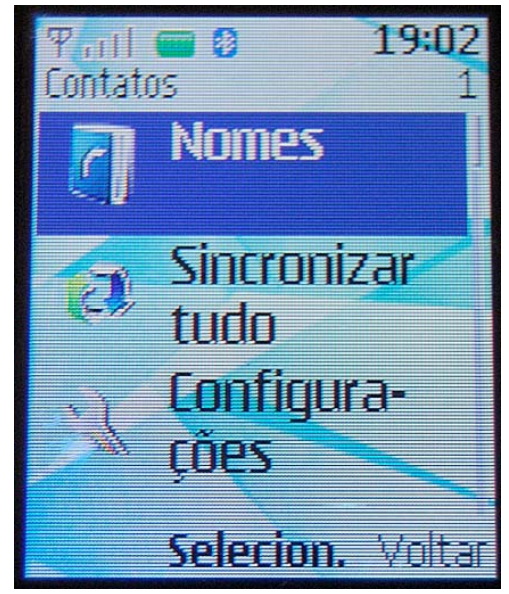

Figura 3: Apoio a seleção de opções

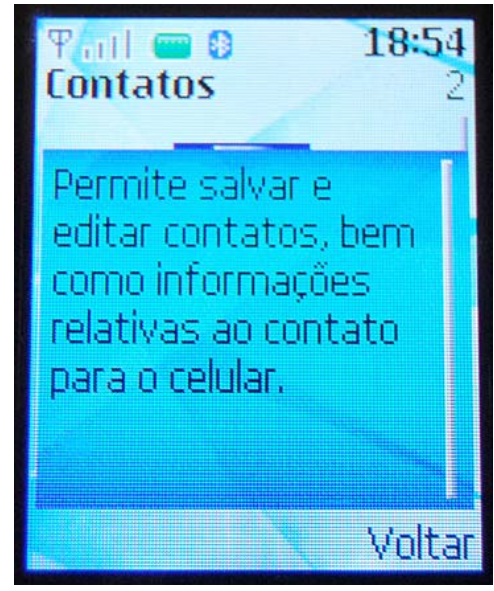

Aos usuários intermediários e experientes deste tipo de interface, é garantido o apoio à sua personalização por meio de atalhos e configurações. Para usuários novatos que necessitam de uma interface intuitiva e, principalmente, condutiva, não há suporte à personalização.

\section{Construção do modelo de análise}

A partir da avaliação heurística, aplicou-se o Conceito de Modularidade na construção de um modelo de análise com os seguintes objetivos: (i) permitir uma abordagem antropocentrada; (ii) simplificar o contexto (interface digital), de modo a facilitar a aprendizagem e gerar uma menor carga cognitiva durante a possível interação; e (iii) disponibilizar os comandos sob demanda com o intuito de reduzir a complexidade da interface.

O Conceito de Modularidade recomenda o agrupamento de ferramentas e de conteúdos para a projetação de interfaces digitais e ambientes interativos. Para ter acesso a esses módulos o usuário, na primeira interação com a interface digital, será categorizado de acordo com o seu perfil, por meio de um breve quiz sobre a experiência com a realização de tarefas no tipo de interface em questão. Esse questionário pode estar disponível na forma de um manual de instruções junto ao equipamento, de maneira que o usuário tenha acesso imediato a ele quando da aquisição do bem. A partir do resultado obtido, o usuário deve ser instruído a selecionar o perfil de usuário no sistema (figura 4). 
Figura 4: Tela definição de perfil

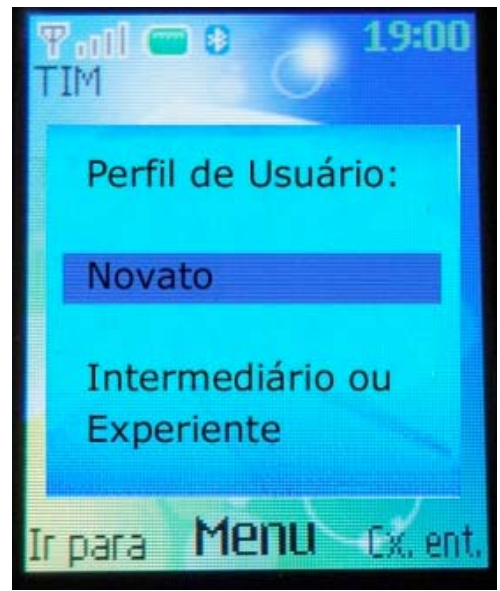

Figura 5: Tela Menu para usuários novatos

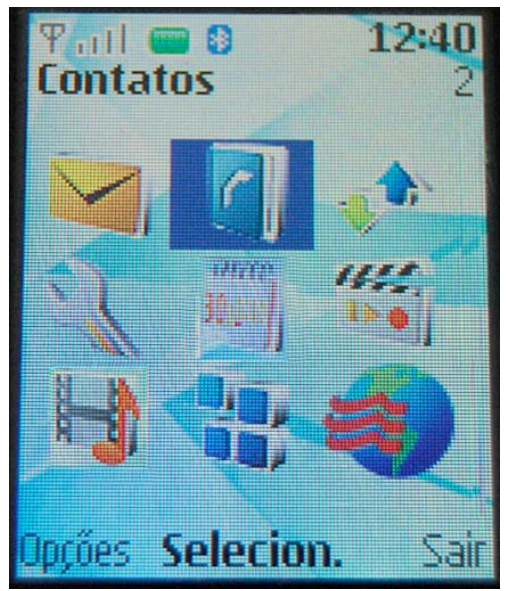

Ainda, em qualquer momento de interação, o usuário deve ter à sua disposição o recurso de mudar de perfil de acordo com a sua preferência, seja pelo seu nível de desenvolvimento nas tarefas, seu conhecimento adquirido ou seu repertório. Pode ser garantida a flexibilidade na mudança de perfil, de forma que um usuário novato possa experimentar a interface de usuário intermediário ou experiente e, caso decida retornar ao perfil anterior, tenha a possibilidade de mudança de perfil através de um ícone a ser disponibilizado na seção Menu. Para este estudo não foi desenvolvido uma proposta de ícone, pois é sabido que para a sua projetação são necessários estudos aprofundados, envolvendo a avaliação das alternativas com usuários.

Aos usuários novatos deve ser apresentada uma interface mais simplificada. Para garantir essa qualidade, a tela Menu disponibiliza apenas as principais ferramentas necessárias para interagir com o celular, suprimindo o recurso Serviços TIM. A interface sugerida disponibiliza as ferramentas principais para a interação com o celular e garante que a seção mais utilizada pelo usuário receba o destaque com o quadrado azul de fundo (figura 5).

O Conceito de Modularidade, por ter suas bases teóricas nos conhecimentos da ergonomia de interfaces, de usabilidade e de hipermídia adaptativa, também prioriza que as interfaces sejam condutivas, devendo ser mantido, portanto, o recurso de Orientação Direta (figura 6).

Figura 6: Orientação direta para usuários novatos

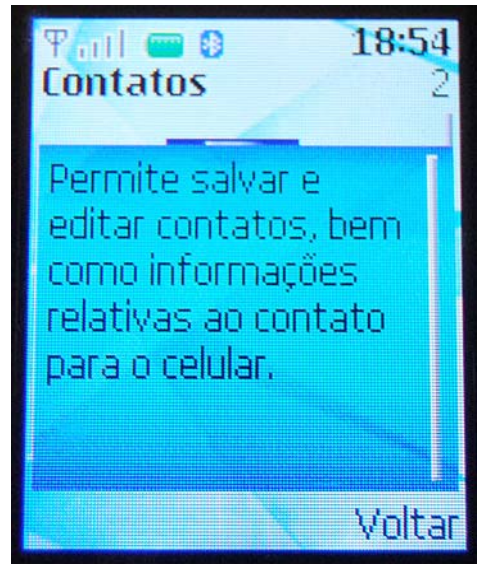

Figura 7: Lista de contatos para usuários novatos

\begin{tabular}{l}
\hline Plomes \\
Adri \\
Adriana \\
Advogado Fábio L... \\
Ak Deise \\
Albatroz \\
Alemoa \\
Duroues Detalhes voltar \\
\hline
\end{tabular}

$\mathrm{Na}$ tela de Lista de Contatos, o usuário pode localizar o nome ou telefone desejado para a realização da chamada telefônica com o uso da barra de rolagem (figura 7). Ou, ainda, escolhendo 
Opções, no canto inferior esquerdo, pode pesquisar por um mecanismo de busca o nome ou telefone desejado, como pode ser visto nas figuras 8 e 9 . Recomenda-se manter o recurso original do equipamento, que aciona automaticamente o mecanismo de busca em resposta ao clique em uma letra do teclado, gerando uma oportunidade de aprendizagem de atalhos que os usuários novatos encontrarão também em outras funcionalidades deste sistema (figura 9).

Figura 8: Lista de opções para usuários novatos

Figura 9: Busca na lista para usuários novatos

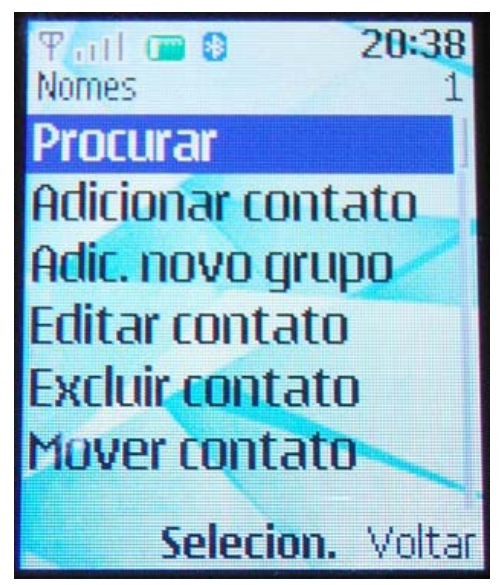

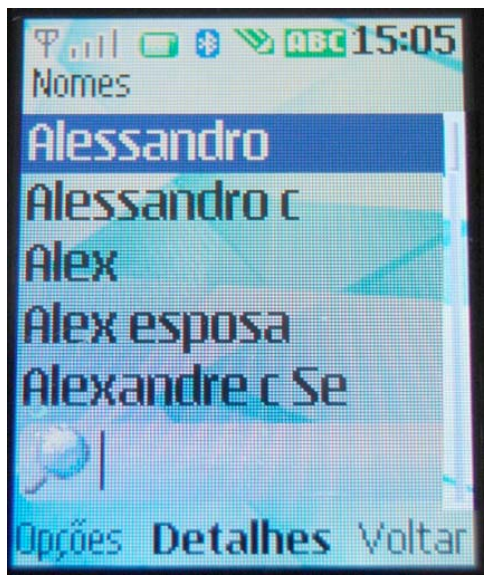

Independente da escolha do caminho, o usuário novato chegará à tela com o nome e o telefone do seu contato da lista, realizando a chamada pelo comando Chamar localizado no centro da parte inferior da tela (figura 10).

Figura 10: Contato selecionado para usuários novatos

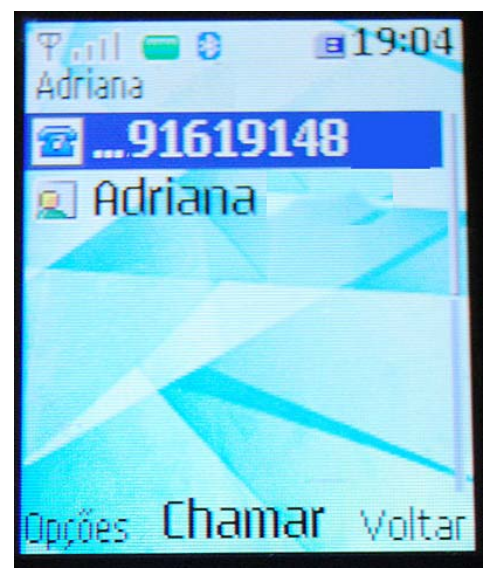

Figura 11: Configurações para usuários novatos

\begin{tabular}{l}
\hline Plill \\
Nomes \\
Procurar \\
Adicionar contato \\
Editar contato \\
Excluir contato \\
Mover contato \\
Configurações \\
Selecion. Voltar \\
\hline
\end{tabular}

Para contemplar as recomendações do Conceito de Modularidade sugere-se que o primeiro nível de recursos da seção Contatos - Nomes, Sincronizar tudo, Configurações, Grupos, Discagens rápidas, Número de serviço, Meus números, Excluir todos os contatos, Mover contatos, Copiar Contatos - constitua um agrupamento denominado Configurações e que o mesmo esteja disponível ao usuário na seção Opções. Por acreditar-se que os usuários não alteram diariamente as configurações, estes recursos estarão acessíveis conforme a demanda do usuário, conforme pode ser visto na figura 11.

\section{Resultados}

Com a aplicação do Conceito de Modularidade, conclui-se que no modelo de análise construído:

- A determinação da seção Contato como padrão de acionamento imediato contempla o principal uso de comunicação da telefonia móvel, adequando-se ao contexto dos usuários novatos; 
- Para a realização da tarefa de realizar uma chamada telefônica selecionando o número pela lista de contatos do telefone celular Nokia 2660 o número de ações foi reduzido a apenas três (03): tela padrão > tela Menu > tela Lista de Contatos;

- A redução no número de ações proporcionará uma minimização de custo pela diminuição do tempo de uso do celular com a iluminação de tela, induzindo a uma redução na frequência de recarga do aparelho;

- O menor número de ações para a realização da tarefa reduz a carga cognitiva de interação;

- O agrupamento do primeiro nível de recursos da seção Contatos em Opções evita a duplicidade do uso do ícone do telefone sobre o livro, que originalmente é usado com os significados de Contatos e Nomes;

- O agrupamento de recursos por objetivo de tarefa facilita a navegação para os usuários novatos, uma vez que as longas listas de opções de cada seção serão acessadas apenas sob demanda;

- As barras de rolagem devem ser mantidas sempre que o usuário tiver a possibilidade de navegação do tipo para cima e para baixo, mantendo, assim, a consistência interna;

- Foi mantida a consistência externa, com o uso de ícones e metáforas semelhantes em outros modelos e em outros celulares;

- O apoio à seleção de Contatos na tela Menu foi mantido, sugerindo-se a aplicação de Orientação Direta nos recursos disponíveis na seção Opções.

\section{Considerações finais}

A avaliação heurística demonstrou que a interface digital apresenta ruídos de usabilidade nos princípios para projetos de interação móvel, principalmente no tangente aos itens: consistência interna, minimização dos custos e da carga de trabalho, facilidade de navegação, apoio à seleção de opções, cuidado com a rolagem da tela e apoio à personalização da interface.

A interface digital é pouco adequada ao contexto do usuário novato, considerando especialmente casos em que o mesmo esteja em movimento e/ou passível de influências ambientais que the causem déficit de atenção e lhe prejudiquem a interação com o equipamento móvel.

As telas apresentam certa consistência externa, dada a presença de ícones e metáforas semelhantes aos existentes em outros modelos e em outros celulares; entretanto, apresentam falhas de consistência interna quanto à estrutura de navegação, à inconstância da presença de barra de rolagens e de padrões de telas, e ao exibir um ícone em duplicidade com significados distintos.

A interface não visa à otimização do processo de interação, havendo a necessidade de um número considerável de ações para a realização da tarefa, o que aumenta o custo de uso do equipamento de maneira indireta. Ainda, o número excessivo de ações para a realização da tarefa implica em uma carga cognitiva de interação, que também pode ser agravada pela inconstância de significado do ícone representado pelo fone sobre o livro.

A navegação não é facilitada para os usuários novatos, tendo em vista que algumas telas apresentam longas listas de recursos, fato agravado pela presença inconstante da barra de rolagem de tela. O sistema de navegação não é padrão: enquanto algumas telas permitem a navegação por intermédio da barra de rolagem, em outras a seleção de funções é feita através da movimentação de uma faixa azul.

O apoio à seleção de opções é inconstante, pois não é oferecido em todas as telas com lista de recursos ou ícones. O sistema garante parcial apoio às interrupções, uma vez que recupera as ações apenas quando o usuário demora a tomar uma decisão, e não nos casos de interrupções de ordem técnica.

Aos usuários intermediários e experientes deste tipo de interface, é garantido o apoio à sua personalização por meio de atalhos e configurações. Para usuários novatos que necessitam de uma interface intuitiva e, principalmente, condutiva, não há suporte à personalização. 
Constatou-se a viabilidade de aplicação do Conceito de Modularidade na construção de um modelo de análise para esta interface digital. E conclui-se, detalhadamente, que a determinação da seção Contato como padrão de acionamento imediato (principal uso de comunicação da telefonia móvel) favorece a adequação do contexto aos usuários novatos. Um número máximo de ações para a navegação pode ser garantido com o agrupamento de recursos por objetivo de tarefas, que permitam o acesso de informações por demanda. Ainda, a redução de número de ações pode proporcionar uma redução na carga cognitiva para o usuário e uma minimização dos custos de interação.

Respeitando as características de interação dos usuários novatos, devem ser garantidas a estes interfaces digitais com consistência interna de navegação e de disponibilização da informação, bem como apoio à seleção de opções e recursos do tipo "ajuda".

Acredita-se que o Conceito de Modularidade aplicado neste modelo de análise proporciona uma abordagem antropocentrada, através de uma simplificação do contexto de interação e da liberação de ferramentas sob demanda. Espera-se favorecer a interação e facilitar a tomada de decisão por parte dos usuários novatos.

Ainda, espera-se que este estudo contribua para o enriquecimento das pesquisas sobre ergonomia e usabilidade direcionada para usuários novatos, área de pesquisa ainda muito carente de informações.

\section{Recomendações para futuros trabalhos}

Neste estudo, a modularidade das interfaces digitais apoiou-se na funcionalidade das ferramentas para a realização da tarefa, embora se acredite ser de suma importância a verificação de outros critérios para a organização das ferramentas.

Este estudo teve o propósito de aplicação do Conceito de Modularidade em um modelo de análise de interface de celular restrito à seção Contatos. Para futuros trabalhos, sugere-se a aplicação desse conceito nas demais funcionalidades e ferramentas do equipamento, bem como a construção dos modelos de análises para as mesmas.

Para a aplicação do Conceito de Modularidade em todas as ferramentas e conteúdos deste telefone celular, sugere-se o estudo sobre a viabilidade de que a seção Configurações agrupe subseçães do tipo Configuração Contatos, Configuração Mensagens, Configuração Ligações, Configuração Galeria, Configuração Mídia, Configuração Organizador, Configuração Aplicativos e Configuração Web, partindo da premissa de que as configurações do aparelho não serão alteradas constantemente.

Recomenda-se a avaliação deste modelo de análise ampliado por meio de testes de usabilidade junto a usuários novatos.

Ainda, sugere-se o estudo aprofundado sobre a linguagem iconográfica utilizada na interface analisada considerando a presença de um mesmo ícone para diferentes seções, como no caso do ícone do livro com o telefone na capa - usado para representar Contatos e Nomes.

\section{Referências}

BRUSILOVSKY, P.; KARAGIANNIDIS, C.; SAMPSON, D. (2004). Layered evaluation of adaptive learning systems. Int. J. Cont. Engineering Education and Lifelong Learning. Vol. 14, Nos. 4/5, pp.402-421.

CLANCEY, William J. (2005). Observation of Work Practices in Natural Settings. To appear in A. Ericsson, N. Charness, P. Feltovich \& R. Hoffman (Eds.), Cambridge Handbook on Expertise and Expert Performance. New York: Cambridge University Press, pp. 127-145.

CYBIS, Walter; BETIOL, Adriana; FAUST, Richard. (2007). Ergonomia e Usabilidade: conhecimentos, métodos e aplicações. São Paulo: Novatech Editora.

DIAS, Lisandra de Andrade. (2008). Ambientes modulares: uma proposta de conceito para concepção de ambientes interativos com foco em usuários novatos. São Paulo: Blucher Acadêmico.

DIAS, Lisandra de Andrade. (2007). Conceito de Modularidade - construção de um modelo de 
análise. 2007. 50f. Monografia (Graduação em Design) - Faculdade Barddal de Artes Aplicadas. Florianópolis.

ENDSLEY, M. R. (1995).Toward a theory of situation awareness in dynamic systems. Human Factors, 37(1), 85-104.

GRISON, B. (2004). Des Sciences Sociales à l'Anthropologie Cognitive. Lês généalogies de la Cognition Située, Disponível em: <http://www.activites.org/v1n2/grison. pdf>. Acesso em: 23 de julho de 2006. Revue Activités, 1 (2), 26-34.

GIBSON, James J. (1987). The ecological approach to visual perception. Boston: Houghton-Mifflin.

HUTCHINS, Edwin et al. (2000). Distributed Cognition: toward a new foundation for humancomputer interaction research. San Diego: University of California.

LAVE, Jean; WENGER, Etienne. (1998). Situated Learning. Cambridge University Press.

SUCHMAN, Lucy A. (1987). Plans and Situated Actions. The problem of human machine communication. Cambridge University Press.

TAVARES, Monica. (2010). Número de celulares no Brasil é maior que o de habitantes. In: $O$ Globo. Disponível em: <http://oglobo.globo.com/economia/mat/2010/11/18/numero-decelulares-no-brasil-maior-que-de-habitantes-923047874.asp> Acesso em: 18 de novembro de 2010.

THEUREAU, J. (2004). L'hypothèse de la cognition (ou action) situèe et la tradition d'analyse de I'ergonomie de langue française. Disponível em: <http://www. activites.org/v1n2/ theureau.pdf>. Acesso em: 23 de julho de 2006. Revue Activités, 1(2), 11-25.

VANZIN, Tarcísio. (2005). TEHCo-Modelo de ambientes hipermídia com tratamento de erros, apoiado na teoria da cognição situada. UFSC, 2005. Tese de doutorado. Programa de PósGraduação em Engenharia de Produção. Florianópolis-SC: UFSC.

\section{Sobre a autora}

Lisandra de Andrade Dias, Dr. Eng., UFSC, possui pesquisas nas áreas de ergonomia de interfaces, design de interfaces e design gráfico, suas principais publicações são seus livros sobre Conceito de Modularidade.

lisandra.andrade@gmail.com 